\title{
Two Novel Ways for Low Voltage Ride-through of Double Fed Induction Generator
}

\author{
Peng Zhao ${ }^{\text {a }}$, Jing Jia ${ }^{1, b}$, Ruiqi Wang ${ }^{1, \mathrm{c}}$, Yong Zhang, Qingbo Mao, Shuai Zhao \\ ${ }^{1}$ Shandong Electric Power Research Institute of State Grid Corporation of China, Jinan, Shandong

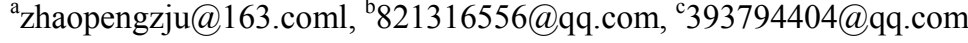

\begin{abstract}
The purpose of this paper is to present two novel methods of improving low voltage ride-through (LVRT) capacity of doubly fed induction generator (DFIG) wind turbines. The first one, combining regular crowbar protection and three switches, enabled us not to consider the insulation of rotor inverter when choosing the value of crowbar resistance. The switches were connected in series with rotor windings between the crowbar and rotor inverter. In the second one, a series dynamic resistor (SDR) was put between DC capacitor and rotor inverter. This method made DFIG wind turbines have the ability to limit rotor currents without improving capacitor voltage and changing the controller algorithm or controller parameters. However, applying the second method, we needed to increase the voltage rating of rotor inverter to avoid the insulation being destroyed. The second method was justified by simulations in Matlab/Simulink.
\end{abstract}

Keywords- crowbar, doubly fed induction generator (DFIG), low voltage ride through (LVRT), series dynamic resistor (SDR), switches, Wind turbine.

\section{INTRODUCTION}

Wind energy, clean and cost-effective, has received much attention recently. According to World Wind Energy Association, the annual growth rate in 2010 was $23.6 \%$ and in June 2011, worldwide wind capacity reached $215 \mathrm{GW}$ [1]. With the development of wind technology, the proportion of wind power to total grid power has increased to the extent that if wind turbines don't remain connected with the grid during voltage dips, the grid will resume slowly; or even worse, it may become unstable. As a result, many countries have required that wind turbines should have the ability to ride through low voltages [2]. In other words, when low voltages occur, wind turbines should maintain connected with the grid and deliver active and reactive power to the grid as required.

Among various types of wind turbines, doubly fed induction generators (DFIGs) have been dominant. That is because they allow variable speed operation, which means that they can adjust rotor speed in response to wind speed to get high efficiency. Also, DFIGs use partial rated converters, reducing the cost of converter when compared with other wind turbines that use full rated converters. However, when stator voltages drop, the rotor currents of DFIG will become much larger than normal values, if rotor converters are unable to provide enough high voltages to control these over currents. As generally, the voltage rating of rotor converters isn't much larger than necessary on cost ground, the over currents will always occur, if we don't take other measures to control rotor currents. In order to prevent large currents from destroying rotor converters during voltage dips, researchers have proposed various solutions for DFIG to ride through low voltages. These solutions can be roughly divided into two types. One is to control components of DFIG without adding supplementary devices. The controlled components are mainly rotor converters $[3,4]$ and blades [5]. The other is to add supplementary devices, such as dynamic voltage restorers [6,7], flexible alternating current transmission systems (FACTSs) [8,9], and resistors [10]-[13]. One can also combine more than one of these strategies like in [9].

This paper proposes two new ways to enhance LVRT capacity of DFIGs. In section III, the first one is presented. This method combines the crowbar with three switches, which are connected in series with rotor windings between the crowbar and rotor inverter. When the crowbar is activated, the three switches are switched off. This enables the value of the crowbar resistance to be very large without destroying the insulation of rotor inverter. Because larger resistance can limit rotor currents better, DFIGs, with this method, will resume its controllability quickly. In section IV, the second strategy with a series dynamic resistor (SDR) will be discussed. The SDR is put between DC capacitor and rotor inverter. For the reason that the math model of rotor inverter with SDR will not change, this strategy enables DFIGs to control rotor currents during fault condition without changing controller algorithm.

\section{The LVRT Method With Switches}

\section{A. Regular crowbar protection}

The commonly used crowbar protection structure is showed in Fig. 1. When the grid voltage drops, the rotor currents will rise sharply, and then the crowbar is activated so that rotor currents flow into the crowbar rather than rotor inverter.

As mentioned in [12], the value of crowbar resistance should be high enough to limit rotor currents. Large resistance, however, will result in large voltage, which may destroy the insulation of rotor windings and rotor inverter. 


\section{B. Method with switches}

The LVRT method with switches is illustrated in Fig. 2. Switch A, B, and C are added to the regular crowbar protection. Immediately after the crowbar is activated, the three switches should be switched off so that the rotor voltages will not affect the insulation of rotor inverter. Instantly before the crowbar is deactivated, we should turn on the switches to make the control of rotor currents resume quickly.

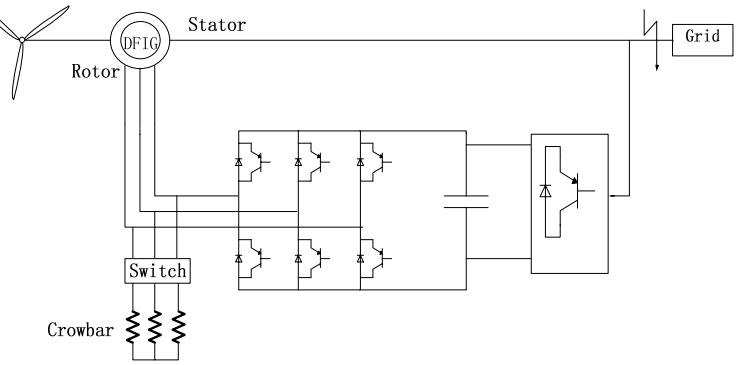

Figure 1 . The structure of the commonly used crowbar protection

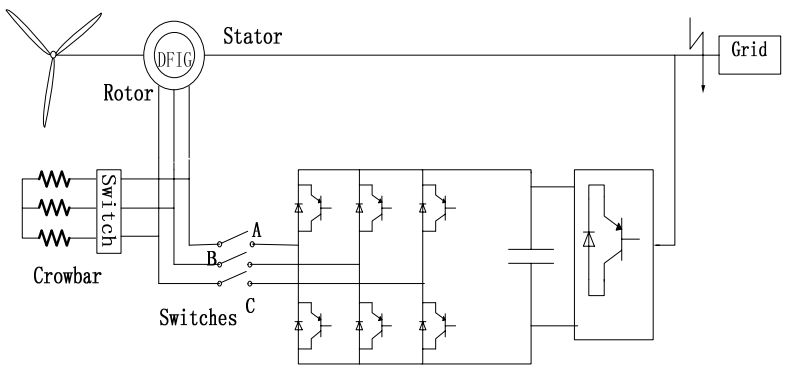

Figure 2. The structure of low voltage ride through strategy combining crowbar protection and switches.

The following simulation examines the effect of the value of crowbar resistance on rotor currents and rotor voltages. The rotor voltages were measured at the junction of rotor windings, the crowbar and rotor inverter. The parameters of the DFIG wind turbine can be found in the appendix. In this simulation, the transformation from stationary circuit variables to synchronously rotating reference frame variables was power-invariable transformation. Before grid faults, the direct and quadrature axis rotor current were $295 \mathrm{~A}$ and $75 \mathrm{~A}$ respectively, and the generator was controlled by stator flux oriented method. For simplicity, the draft rotating speed, $40 \mathrm{~Hz}$, was kept constant, which might not lose accuracy if the fault duration was short and the time constant of draft was relatively big.

Fig. 3 shows the stator voltages. At time $0.4 \mathrm{~s}$, the effective value of phase voltage dropped to $10 \mathrm{~V} / \sqrt{3}$ from $690 \mathrm{~V} / \sqrt{3}$. The crowbar was activated at $0.402 \mathrm{~s}$ and the three switches were switched off at $0.4021 \mathrm{~s}$. The rotor phase currents are shown in Fig. 4 and rotor line voltages in Fig. 5. As we can see from Fig. 4, when crowbar resistances were $0.5 \Omega, 1 \Omega$ and $2 \Omega$ respectively, the maximum fault phase rotor currents reached approximately $1020 \mathrm{~A}, 745 \mathrm{~A}$, and $640 \mathrm{~A}$ respectively. Fig. 5 shows the corresponding line voltages of rotor windings. The maximum line voltages were about $955 \mathrm{~V}, 1300 \mathrm{~V}$ and $2150 \mathrm{~V}$ respectively. To some extent, the simulation results verify that for the crowbar protection, a higher value of crowbar resistance results in lower rotor currents and higher rotor voltage.

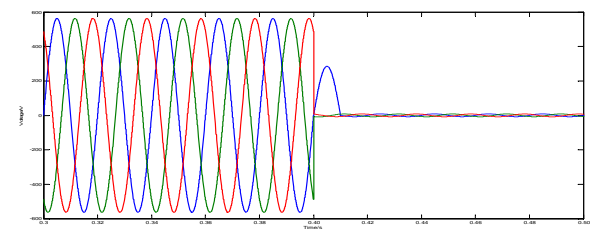

Figure 3. The stator voltages of the DFIG wind turbine.
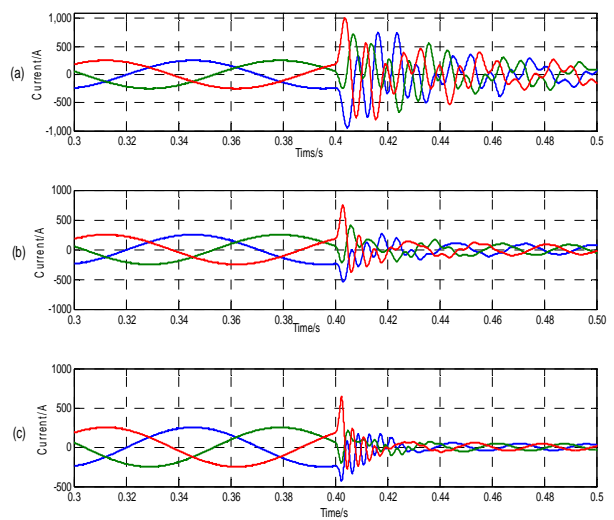

Figure 4. The rotor phase currents of the DFIG wind turbine : the value of crowbar resistance is (a) $0.5 \Omega$ (b) $1 \Omega$ (c) $2 \Omega$.
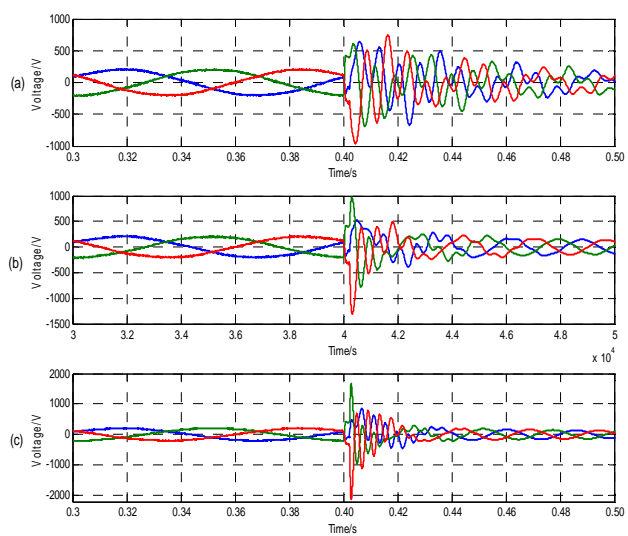

Figure 5. The rotor line voltages of the DFIG wind turbine: the value of crowbar resistance is (a) $0.5 \Omega$ (b) $1 \Omega$ (c) $2 \Omega$. 
Although, with this method, we needn't take into account the insulation of rotor inverter, we still needed to consider the insulation of rotor windings. Consequently, the maximum value of crowbar resistance would largely depend on the voltage rating of rotor windings.

For the crowbar protection or the method with switches, the criteria to determine the value of crowbar resistance can be found in [11]-[12]. One important issue for the determination is generator's fault currents, which are analyzed in [14]-[15]. Moreover, after the crowbar is deactivated, to make the control of DFIG wind turbine resume without introducing instability problem, some strategies should be adopted, some of which are proposed in.

\section{LVRT Method With A SERIES DyNAMIC RESISTOR (SDR)}

Unlike crowbar protection, the method with a series dynamic resistor, illustrated in Fig. 6, can keep its controllability during fault conditions. In normal operation, the switches of SDR are turned on and the current don't flow through the resistor, while in fault operation, the switch is turned off and thereby the current will flow through the resistor.

\section{A. Model of the new inverter}

The configuration of the inverter with SDR is shown in Fig. 7.

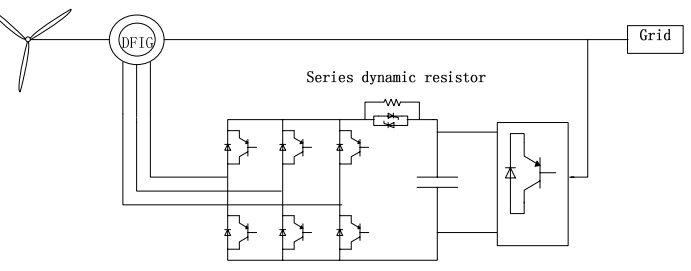

Figure 6 . The structure of the LVRT method with a series dynamic resistor.

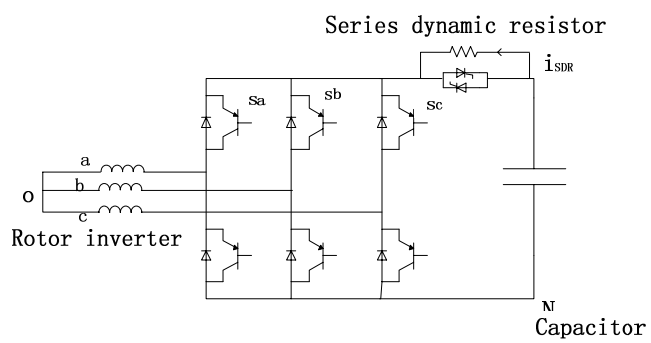

Figure 7. The structure of the new inverter.

From Fig. 7, (1) and (2) express the model of the new inverter. Interestingly, when SDR isn't added to the rotor inverter, the value of SDR being zero, the model of the inverter is also expressed by (1) and (2). Accordingly, we can conclude that after SDR is activated, the math model of the inverter doesn't change. This implies that if our control goals of rotor inverter don't change after the activation of SDR, the controller parameters of rotor inverter needn't be changed. Therefore one of SDR's advantages is that this method eliminates the complexity of control coordination between normal and fault conditions.

$$
\begin{gathered}
U_{d r}=R_{r} i_{d r}+\omega_{f r} \psi_{q r}+\frac{d \psi_{d r}}{d t} \\
U_{q r}=R_{r} i_{q r}+\omega_{f r} \psi_{d r}+\frac{d \psi_{q r}}{d t}
\end{gathered}
$$

Though the new inverter's model (1) and (2), can't be verified completely through theoretic analysis. In the following simulation, the parameters of the DFIG wind turbine are shown in the appendix. The reference direct and quadrature axis rotor currents were $295 \mathrm{~A}$ and $75 \mathrm{~A}$ respectively. Other simulation conditions were the same as in section III. Before $0.4 \mathrm{~s}$, SDR wasn't activated, while at $0.4 \mathrm{~s}$, SDR was activated, and then SDR was deactivated at $0.5 \mathrm{~s}$. The value of SDR was $1 \Omega$. Fig. 8 shows the direct and quadrature axis rotor currents and the activation signal of SDR. As we can see from Fig. 8, after SDR was activated and deactivated, the rotor currents almost didn't change. Because the control algorithm wasn't changed, the simulation results, to some extent, justify the new inverter's math model.

\section{B. SDR's effect on LVRT capacity}

The SDR's effect on LVRT capacity of DFIG wind turbines was studied by simulation. The parameters of the wind turbine are shown in the appendix. Before grid faults, the direct and quadrature axis rotor current were 295A and $75 \mathrm{~A}$ respectively. For simplicity, the draft rotating speed, $40 \mathrm{~Hz}$, was kept constant. The stator voltages dropped at $0.4 \mathrm{~s}$ and resumed at $0.6 \mathrm{~s}$. During voltage dips, SDR was activated at $0.402 \mathrm{~s}$ and deactivated at $0.5 \mathrm{~s}$. During voltage recovery, SDR was activated at $0.602 \mathrm{~s}$ and deactivated at $0.8 \mathrm{~s}$. The values of SDR were $0.5 \Omega, 1 \Omega, 3 \Omega$, and $5 \Omega$ respectively. The effective value of stator phase voltage dropped to $103.5 \mathrm{~V} / \sqrt{3}$ from $690 \mathrm{~V} / \sqrt{3}$. That is, the stator voltage dropped to $15 \%$. The controller parameters of rotor inverter and the reference rotor currents kept changeless through the whole process. Fig. 9 shows the stator voltages and activation signal of SDR. The phase rotor currents are shown in Fig.10 and the line rotor voltages in Fig. 11.
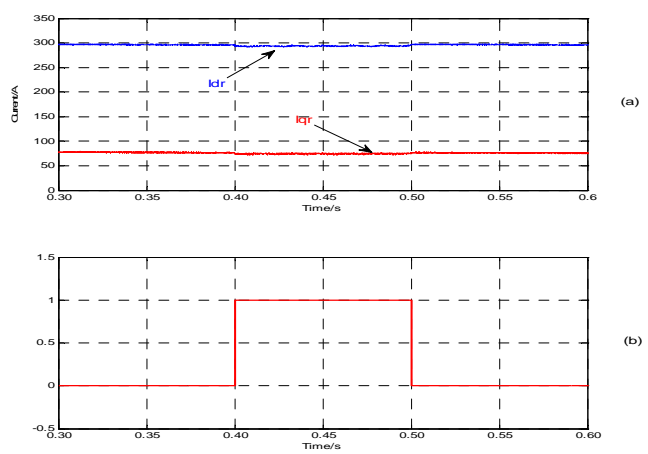

Figure 8. (a) Direct and quadrature rotor currents; (b) SDR activation signal (1 means activation). 

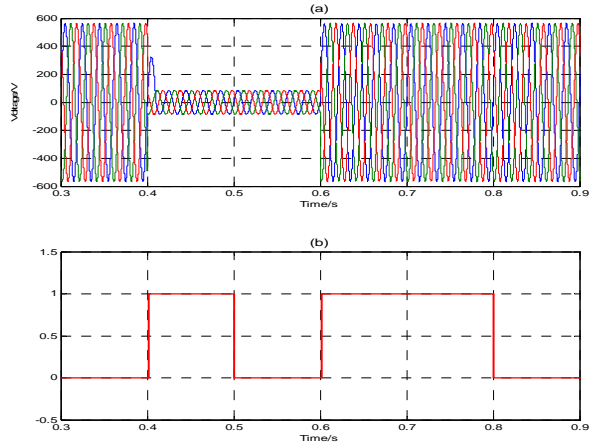

Figure 9. (a) Stator voltages, dropping to $15 \%$; (b) activation signal of SDR (1 means activation).
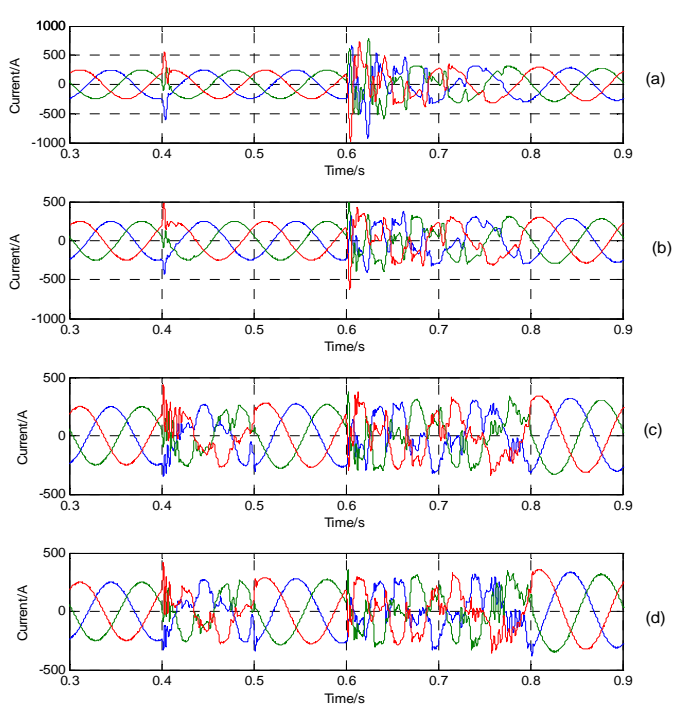

Figure 10 . The rotor phase currents for $15 \%$ fault: value of SDR is (a) $0.5 \Omega$; (b) $1 \Omega$; (c) $3 \Omega$; (d) $5 \Omega$.
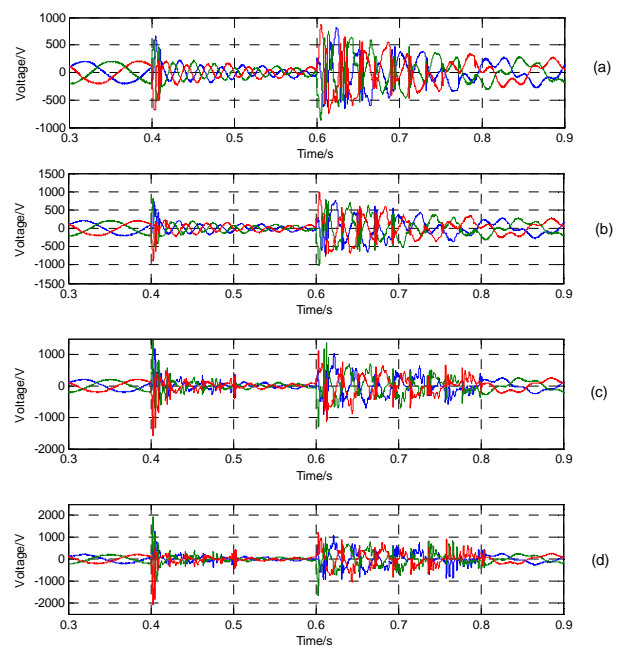

Figure 11 . The rotor line voltages for $15 \%$ fault the : the value of SDR is (a) $0.5 \Omega$; (b) $1 \Omega$; (c) $3 \Omega$; (d) $5 \Omega$.
From Fig. 10, we could get: (a) during voltage dips, a larger value of SDR resulted in a smaller peak value of rotor currents. When SDRs were $0.5 \Omega, 1 \Omega, 3 \Omega, 5 \Omega$ respectively, the maximum rotor fault currents were about 560A, 480A, 435A and 420A respectively. This also meant that the larger SDR was, the less the rotor currents would increase after the activation of SDR; (b) during voltage recovery, a larger value of SDR also resulted in a smaller peak value of rotor currents. Also, a large value of SDR, such as $3 \Omega$ and $5 \Omega$ in this case, would make the maximum rotor currents during voltage recovery smaller than the maximum rotor currents during voltage dips; (c) a larger value of SDR would result in more harmonic components during SDR's activation.

From Fig. 11, we could get: (a) during voltage dips, a larger value of SDR resulted in a bigger peak value of rotor voltages. When SDRs were $0.5 \Omega, 1 \Omega, 3 \Omega, 5 \Omega$ respectively, the maximum rotor fault voltages were about $685 \mathrm{~V}, 890 \mathrm{~V}, 1590 \mathrm{~V}$ and $2100 \mathrm{~V}$ respectively; (b) during voltage recovery, a larger value of SDR also resulted in a bigger peak value of rotor voltages. However, a large value of SDR, such as $3 \Omega$ and $5 \Omega$ in this case, would make the maximum rotor voltages during voltage recovery smaller than the maximum rotor voltages during voltage dips; (c) a larger value of SDR would result in more harmonic components during SDR's activation.

Despite the need to raise the voltage rating, the method with SDR may be relatively cost-effective when compared with other methods which need to increase the capacitor voltage to control rotor currents, because increasing the capacitor voltage means increasing the voltage ratings of both rotor inverter and rotor rectifier.

As for the reasons why the LVRT method with SDR can control the rotor currents without improving the capacitor voltage, although the authors don't know them exactly, the authors' biggest guess is that after the activation of SDR, the change of voltage between point 0 and point $\mathrm{N}$ in Fig. 7 leads to that ability

\section{SUMMARY}

The purpose of this paper is to suggest two novel methods for improving the low voltage ride-through capacity of DFIG wind turbines. Analysis showed that the first one with switches enabled us not to consider the insulation of rotor inverter when choosing the value of crowbar resistance. However, in this method, we still needed to consider the insulation of rotor windings. As for the second method with SDR, the simulation results demonstrated that this method could limit rotor currents without loss of controllability. Another advantage of this method was that in fault operation the controller algorithm could keep changeless, for the reason that the math model of rotor inverter with SDR wouldn't change. Not perfectly, although we didn't need to improve the voltage rating of rotor rectifier, we had to improve the voltage rating of rotor inverter to assure rotor currents' controllability. In further study, two aspects could be investigated. One is the exact reasons why the LVRT method with SDR can control rotor 
currents without improving the capacitor voltage. The other is the criteria for choosing the value of SDR.

\section{APPENDIX}

TABEL 1 NOMENCLATURE

\begin{tabular}{|c|l|}
\hline \multicolumn{1}{|c|}{$i, v, R$} & Current, voltage, resistor \\
\hline$L, \psi$ & Inductance, flux \\
\hline$\theta_{f}$ & the angular displacement of reference frame \\
\hline$\theta_{r}$ & the angular displacement of the rotor \\
\hline$\omega_{f}$ & the angular velocity of reference frame \\
\hline$\omega_{r}$ & the angular velocity of the rotor \\
\hline Subscripts & \\
\hline$S D R$ & Series dynamic resistor subscript \\
\hline$a, b, c$ & Phase a, phase b, phase c subscripts \\
\hline$D C$ & DC capacitor subscript \\
\hline$d, q, 0$ & Direct, quadrature, zero axis subscripts \\
\hline
\end{tabular}

TABel 2 Parameters of THE DFig Used IN ThIS STUdy

\begin{tabular}{|l|l|}
\hline Parameter & value \\
\hline Effective stator line voltage & $690 \mathrm{~V}$ \\
\hline Frequency & $50 \mathrm{~Hz}$ \\
\hline Rotor speed & $40 \mathrm{~Hz}$ \\
\hline Stator resistance & $5 \mathrm{e}-2 \Omega$ \\
\hline Rotor resistance & $5 \mathrm{e}-2 \Omega$ \\
\hline Stator leakage inductance & $2 \mathrm{e}-5 \mathrm{H}$ \\
\hline Rotor leakage inductance & $1 \mathrm{e}-5 \mathrm{H}$ \\
\hline Magnetizing inductance & $5 \mathrm{e}-3 \mathrm{H}$ \\
\hline Number of pole pairs & 1 \\
\hline Stator/rotor ratio & 1 \\
\hline Capacitor voltage & $400 \mathrm{~V}$ \\
\hline
\end{tabular}

\section{REFERENCES}

[1] http://wwindea.org.

[2] M. Tsili, and S. Papathanassiou, "a review of grid code technical requirements for wind farms," IET Renew. Power Gener., vol. 3, iss. 3, pp. 308-332, 2009.

[3] Lie $\mathrm{Xu}$, and Yi Wang, "Dynamic modeling and control of DFIG-based wind turbines under unbalanced network conditions," IEEE Trans. Power Systems, vol. 22, no. 1, pp. 314-323, Feb. 2007.
[4] Dawei Xiang, Li Ran, Peter J. Tavner, and S. Yang, "Control of a doubly fed induction generator in a wind turbine during grid fault ride-through," IEEE Trans. Energy Conversion, vol. 21, no. 3, pp. 652-662, Sep. 2006.

[5] Aung Ko Thet and H. Saitoh, "Pitch control for improving the low-voltage ride-through of wind farm," Transmission \& Distribution Conference \& Exposition: Asia and Pacific, Oct. 2009.

[6] Christian Wessels, Fabian Gebhardt, and Friedrich Willhelm Fuchs, "Fault ride-through of a DFIG wind turbine using a dynamic voltage restorer during symmetrical and asymmetrical grid faults," IEEE Trans. Power Systems, vol. 26, no. 3, pp. 807-815, Mar. 2011.

[7] Patrick S. Flannery, and Giri Venkataramanan, "A fault tolerant doubly fed induction generator wind turbine using a parallel grid side rectifier and series grid side converter," IEEE Trans. Power Electronics, vol. 23, no. 3, pp. 1126-1135, May. 2008

[8] K. E. Okedu, S. M. Muyeen, Rion Takahashi, and J. Tamura, " Participation of facts in stabilizing DFIG with crowbar during grid fault based on grid codes," in 2011 IEEE conference and exhibition, Dubai, pp. 365-368.

[9] Zhou Linyuan, Liu Jinjun, and Liu Fangcheng, "Low voltage ride-through of wind farms using STATCOM combined with series dynamic breaking resistor," in 2010 2nd IEEE Int. Symp. Power Electronics for Distributed Generation Systems, pp. 841-845.

[10] Andreas Dittrich, and Alexander Stoev, " Comparison of fault ride-through strategy for wind turbines with DFIM generators," in 2005 European Conf. Power Electronics and Application.

[11] J. H. Zhang, X. Y. Chen, Bing Wang, Ping Wang, and Hao-Ming Liu, "Three-phase short circuit analysis of DFIG-based wind generation and the crowbar biggest resistance setting," in 2009 IEEE Conf. SUPERGN.

[12] Johan Morren, and Sjoerd W. H. de Haan, "Short-circuit current of wind turbines with doubly fed induction generator," IEEE Trans. Energy Conversion, vol. 22, no. 1, pp. 174-180, May. 2007.

[13] W. J. Chen, David Atkinson, Hamza Chaal, and Milutin Jovanovic, "Experimental and simulation comparison for timer action crowbar of doubly-fed induction generator," in 2011 IEEE Asia-Pacific Power and Energy Engineering Conf. .

[14] M. S. Vicatos, and J. A. Tegopoulos, "Transient state analysis of a doubly fed induction generator under three phase short circuit" IEEE Trans. Energy Conversion, vol. 6, no. 1, pp. 62-68, Mar. 1991.

[15] J. Lopez, P. Sanchis, X. Roboam, and L. Marroyo, "Dynamic behavior of the doubly fed induction generator during three-phase voltage dips," IEEE Trans. Energy Conversion, vol. 22, no. 3, pp. 709-717, Sep. 2007.

[16] J. Lopez, E. Gubia, P. Sanchis, X. Roboam, and L. Marroyo, "Wind turbines based on doubly fed induction generator under asymmetrical voltage dips," IEEE Trans. Energy Conversion, vol. 23, no. 1, pp. 321-330, Mar. 2008.

[17] Paul C. Krause, Oleg Wasynczuk, and Scott D. Sudhoff, Analysis of Electric Machinery and Drive Systems, 2nd ed. USA: IEEE-Willey, 2002, pp. 109-140. 